\title{
ENVIRONMENTAL IMPACT ASSESSMENT OF A METRO INFRASTRUCTURE FACILITY CONSTRUCTION BY MODELLING WATER AND SOIL POLLUTION
}

\author{
DIMITRIOU G. ${ }^{1,2}$ \\ PAPADOPOULOU M.P. ${ }^{1,3, *}$
}

\author{
${ }^{1}$ School of Science and Technology, Hellenic Open University \\ 18 Aristotelous Parodos, Patra 23226 \\ ${ }^{2}$ Engineering Geology Department \\ ATTIKO METRO SA, Mesogion 191-193, Athens 11525 \\ ${ }^{3}$ School of Rural and Surveying Engineering \\ National Technical University of Athens \\ 9 Iroon Polytechniou, Zografou 15780, Athens, Greece
}

Received: $17 / 01 / 2014$

Accepted: $21 / 07 / 2014$

Available online: 24/07/2014 *to whom all correspondence should be addressed: e-mail: mpapadop@mail.ntua.gr

\section{ABSTRACT}

The construction of large infrastructure projects such as highways, railroads, landfills, airports, harbours offers great social-economic opportunities for the development of a region; it is also mainly responsible for the deterioration of natural environment in the greater areas where these projects are located. The goal of environmental impact assessment (EIA) that is carried out before the construction of such a project is to propose measures and actions that will limit negative environmental impacts during its construction and operation phases. The common perception is that large scale infrastructure projects can only damage natural environment even though very strict environmental requirements are imposed by the Authorities. This was not the case in Eleonas Attikis region in Greece where METRO facilities were built. During the construction phase, hazardous solid wastes were found buried in the urban area where METRO facilities (station, tunnel and depot) were located, raising serious environmental issues in natural and human environment in the region.

The protection and restoration of environment in an uncontrolled waste dumpsite require accurate estimation of subsurface pollution extent and intensity. The scope of the present analysis is to map the contamination in the aquifer of Eleona Attikis where METRO facilities (station, tunnel and depot) were built. Numerical modelling approaches were used to estimate environmental impacts of this project to soil and water resources in the greater region. The results have shown that the removal of buried solid wastes to construct METRO station and depot was crucial in order to eliminate negative impacts in soil and subsurface water resources. An impact assessment of hazardous solid wastes buried for many years in the aquifer was also performed. The findings of this analysis proved that the implementation of a large infrastructure project such as the one in Eleona Attikis Greece was environmentally beneficial for the region.

Keywords: Environmental impact assessment, soil and subsurface water map pollution, METRO infrastructure facility, uncontrolled solid wastes disposal, aquifer remediation actions, numerical modelling and pollution monitoring

\section{Introduction}

Previous research works have shown that implementation of large scale infrastructure works may cause changes in the environmental conditions of a region. For that reason, an environmental assessment 
should be undertaken for a) individual projects, such as dams, highways, airports or factories, on the basis of Directive 85/337/EEC (known as 'Environmental Impact Assessment' - ElA Directive) and b) plans or programmes on the basis of Directive 2001/42/EC (known as 'Strategic Environmental Assessment' - SEA Directive) in order to first assess impacts and then propose specific actions to control them. The goal of both Directives is to ensure that plans, programmes and projects with significant impacts on natural and human environment are designed subject to an environmental assessment, prior to their approval and implementation.

Due to economic growth and population increase the last few decades, solid wastes volume has increased and environmental impacts from their uncontrolled disposal were more intense. Illegal dumpsites are sources of air, soil and water pollution and therefore they should stop operating or should be replaced immediately by sanitary landfills (Tchobanoglous and O'Leary, 2002). The main environmental problems caused by uncontrolled dumpsites are mainly due to lack of a) water proof systems at the bottom and the slopes of a landfill, b) leachate drainage system, c) biogas management system, d) flood control, e) fire protection system, f) site fencing, g) visual screening and landscape improvement works and h) environmental monitoring (Lolos et al., 2007). Collection and management of leachate produced in a landfill is a key factor to obtain protection and remediation of the aquifer. Therefore, the development and application of methodologies for precise tracking of possible contamination source and leakage due to construction failures are very important.

\subsection{Previous Experience}

Although specific procedures that take place during contaminant mass transport in the ground, have already been described with good accuracy in lab scale (Nelson et al. 2003; Wei, 2006; Sharma and Dixit, 2013; Chang and Clement, 2013) however there is an ambiguity of the way that a contaminant is diffused and dispersed in an aquifer underneath a landfill. This is mainly due to the uncertainty related to the determination of necessary aquifer parameters to describe the complex physical, chemical and biological processes that take place in a landfill (El-Fadel et al., 1997). In 1999, Mato (1999) presented the key features of a EIA procedure involving the establishment of sanitary landfills in five municipalities in Tanzania. The risk of potential soil and groundwater contamination was considered extremely high since the sites were composed of high permeability sand soil allowing pollutants to travel great distances in the aquifer.

Several cases determining groundwater leachate pollution using analytical, geophysical and chemical methods were reported in the literature (MacFarlane et al. 1983; Reinhard et al. 1984; Albaiges et al. 1986; Pastor and Hernández, 2012). There are limited references to experimental or mathematical modeling setups that were used to determine groundwater contamination due to uncontrolled solid wastes disposal. An experimental setup was built by Vourdias (2001) to assess the effects of contaminant desorption on the effectiveness of pump - and - treat remediation system in a shallow homogeneous aquifer contaminated by hazardous waste materials illegally disposed in dumpsites. Verwiel et al. (2001) have also developed a groundwater flow model of Gray Wolf aquifer in Central Arizona U.S., to study the most effective way of groundwater drainage in this specific area where a sanitary landfill was operating and more space was needed to dispose urban solid wastes. Additionally Abu-Rukah and Al-Kofahi (2001), after monitoring several physical and chemical parameters in a landfill in El-Akader in Northen Jordan, concluded that the quality of groundwater had been significantly deteriorated due to leachate contamination and as impact, water resources in the region could not be used any more. According to Fatta et al. (2002), the uncontrolled infiltration of leachate into vadose zone and then into saturated zone was considered to be the most serious environmental impact in Ano Liosia Landfill in Greece. In their analysis a groundwater flow and contaminant mass transport model of the region in combination with Ecosim system have been developed, to propose an integrated environmental monitoring and modeling system. Papadopoulou et al. (2007) developed a mathematical model in order to evaluate the degradation risk of groundwater quality in areas with important social and economic interest, in case of landfill leachate contamination. Their results showed that, in case of a toxic groundwater contamination, the contaminant plume, due to the hydrogeological conditions in the 
region such as high hydraulic gradient and permeability, could affect the quality of extracted groundwater.

Rouholahnejad and Sadrnejad (2009) estimated leachate quantities that might infiltrate into the aquifer where a landfill in Lebanon was located based on Hydrological Evaluation of Landfill Performance (HELP) model. The sensitivity analysis showed that changes in the origin of contamination, hydraulic permeability and contaminant dispersion could significantly affect contaminant mass transport. A numerical solution of finite difference contaminant transport equation was also carried by Jhamnani and Singh (2009) to model Bhalaswa aquifer in New Delhi, India where an uncontrolled landfill was operating, without any aquifer protection measurements. The results were in agreement with the observed chloride concentrations in groundwater highlighting serious contamination problems. The inability of Indian administration to account for environmental damages in groundwater resources in the state of Tamil Nadu India was investigated by Venkatachalam (2004). Finally, the evaluation of surface and subsurface water quality in Lagos, Nigeria, proved that uncontrolled wastes disposal in water channels in combination with buried wastes contribute to heavy metal groundwater contamination by violating EPA limits either in maximum values or in time levels (Odukoya and Abimbola, 2010).

\section{MATHEMATICAL MODELING ESTIMATION OF CONTAMINANT PLUME}

Mathematical modeling is used to describe and analyze mechanisms that control groundwater flow and mass transport in order to first determine contaminant plume extent due to leachate production and then propose necessary actions to resolve possible contamination issues. In this analysis groundwater modeling is used to first achieve a good understanding of the physical processes that take place in Eleonas aquifer and then estimate the response of the aquifer after the construction and during the operation of the proposed METRO facilities.

The area of interest is located in the North - Northwest section of Eleonas region in Attikis Prefecture (Greece), east of National highway of Athens - Lamia (Kifissos river), west of Profiti Daniel stream, south of lera Odos street and north of Orfeos street (Figure 1a). The simulated area was approximately $0.8 \mathrm{~km}^{2}$ $(1000 \mathrm{~m} \times 800 \mathrm{~m})$. According to the available historical data, until 1945 agricultural activities were taking place in the area, the following decades there was a dramatic change in land uses considering mainly industrial and commercial activities. In particular, a part of this area was used to quarry clay for the adjacent ceramic industries. After clay was fully excavated at early $80^{\prime} \mathrm{s}$, the area then was used as an uncontrolled wastes dumpsite where urban solid wastes mixed with manmade fill material were disposed.

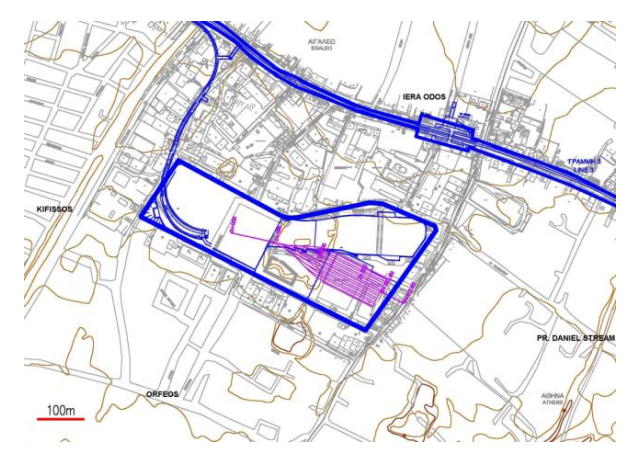

(a)

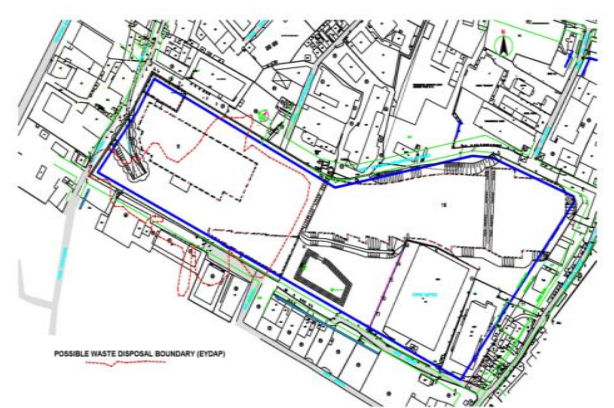

(b)

Figure 1. a) Area of study - Solid lines indicating the locations of METRO tunnel and depot b) Location of buried solid wastes within the area of interest - Dash line

(ATTIKO METRO S.A., 2005; 2009)

In 2000, the construction of the underground tunnel to extent METRO line 3 to Egaleo Town was planned. The project also included the construction of Eleonas station and a METRO depot within the 
area of interest. Geological investigation indicated the existence of wastes covered by manmade deposits (Figure 1b). The current conditions were estimated to be very hazardous since solid wastes were found within a high cultural value urban area close to the historical Athens city center. In addition the existence of an uncontrolled landfill created serious environmental issues to natural environment as well as to public health in terms of drinking water and irrigation quality.

Based on the collected contamination data, ammonia mass transport was chosen to be modeled as it was considered the main soluble groundwater contaminant in the region. Ammonia deprotonates a small fraction of the water to produce ammonium which is an indicator of possible bacterial, sewage and animal waste pollution (WHO, 2003). Following chronologically the construction activities that took place in the area, the developed groundwater model was divided in four stages. In this way, an accurate representation of the changes in the aquifer was obtained. In the first stage, the initial conditions in the region prior to any construction were achieved for a period of one year $(2001-2002)$. During the second stage, the construction of METRO tunnel from 2002 till 2006 as an impermeable boundary significantly changed groundwater hydraulic field. In the third stage, the construction of METRO depot was completed within a 3-year period (2006-2009). Finally in the fourth stage, a prediction of aquifer response under the new conditions from 2009 until 2012 was considered. An additional scenario (Zero Scenario) was also developed to simulate aquifer behavior if no construction activity was considered for a 10-year period during which the construction of the proposed METRO facilities could be achieved.

In-situ geological investigation including a series of sampling boreholes brought into light the existence of a contaminated soil layer under a waste material layer. Numerous sampling boreholes were necessary to accurately determine geological formations, the thickness and extent of waste material with a high level of accuracy despite the great incongruity and anisotropy of the areas' geology (ATTIKO METRO S.A. 2005). In this study, Princeton Transport Code (PTC), a 3-D mathematic algorithm was used to determine the physical characteristics of groundwater flow and contaminant mass transport in the area of interest solving the respective partial differential equations (Eq.1-3) based on a hybrid algorithm solving a finite elements system in horizontal and a finite differences system in vertical direction respectively (Babu et al, 1997; Pinder, 2002).

$\frac{\partial}{\partial x}\left(K_{x x} \frac{\partial h}{\partial x}\right)+\frac{\partial}{\partial Y}\left(K_{y y} \frac{\partial h}{\partial y}\right)+\frac{\partial}{\partial z}\left(K_{z z} \frac{\partial h}{\partial z}\right)-S \frac{\partial h}{\partial t}+\sum_{i=1}^{r} a_{i} \delta\left(x-x_{i}\right) \delta\left(y-y_{i}\right) \delta\left(z-z_{i}\right)=0$

$\mathrm{V}+\mathrm{K} \cdot \nabla \mathrm{h}=0$

$$
\begin{gathered}
\frac{\partial}{\partial x}\left[D_{x x} \frac{\partial c}{\partial x}+D_{x y} \frac{\partial c}{\partial y}+D_{x z} \frac{\partial c}{\partial z}\right]+\frac{\partial}{\partial y}\left[D_{y x} \frac{\partial c}{\partial x}+D_{y y} \frac{\partial c}{\partial y}+D_{y z} \frac{\partial c}{\partial z}\right]+\frac{\partial}{\partial z}\left[D_{z x} \frac{\partial c}{\partial x}+D_{z y} \frac{\partial c}{\partial y}+D_{z z} \frac{\partial c}{\partial z}\right] \\
+Q\left(c^{w}-c\right)-\left(V_{x} \frac{\partial c}{\partial x}+V_{y} \frac{\partial c}{\partial y}+V_{z} \frac{\partial c}{\partial z}\right)-\theta[1+E(c)]\left(\frac{\partial c}{\partial t}\right)=0
\end{gathered}
$$

where $\mathrm{h}$ is the hydraulic head, $\mathrm{K}_{\mathrm{xx}}, \mathrm{K}_{\mathrm{yy}}, \mathrm{K}_{\mathrm{zz}}$ is the hydraulic conductivity in the direction $\mathrm{x}, \mathrm{y}$ and $\mathrm{z}, \mathrm{S}$ is the storage coefficient, $Q_{i}$ is the flow of water (pumping or supplying) at the position $i, \delta()$ is the function delta of Dirac, $r$ is the number of sources of pumping or supplying water, $c$ is the concentration of a contaminant at a point $(x, y, z)$ at time $t, \theta$ is the porosity of the aquifer, $E(c)$ is the absorption equation, $Q$ is the pumping capability, $c^{w}$ is the concentration of pumping water at point $\left(x_{i}, y_{i}, z_{i}\right), V_{x}, V_{y}, V_{z}$, are the components of velocity vector and $D_{x x}, D_{y y}, D_{z z}, D_{x y}, D_{y x}, D_{z y}, D_{y z}, D_{z x}, D_{x z}$ are the dispersion coefficients calculated by the following equations:

$$
\begin{aligned}
& D_{x x}=\left(a_{L} V_{x}^{2}+a_{T} V_{y}^{2}+a_{V} V_{z}^{2}\right) / V+D_{M} \\
& D_{y y}=\left(a_{T} V_{x}^{2}+a_{L} V_{y}^{2}+a_{V} V_{z}^{2}\right) / V+D_{M} \\
& D_{z z}=\left(a_{V} V_{x}^{2}+a_{V} V_{y}^{2}+a_{L} V_{z}^{2}\right) / V+D_{M} \\
& D_{y x}=D_{x y}=\left(a_{L}-a_{T}\right) V_{x} V_{y} / V \\
& D_{y z}=D_{z y}=\left(a_{L}-a_{V}\right) V_{y} V_{z} / V \\
& D_{z x}=D_{x z}=\left(a_{L}-a_{V}\right) V_{z} V_{x} / V
\end{aligned}
$$


where $D_{M}$ is the molecular diffusion coefficient, $a_{L}$ is the longitudinal dispersion, $a_{T}$ is the horizontal component of the traverse dispersion, $\mathrm{a}_{\mathrm{v}}$ is the vertical component of the traverse dispersion.

In Figure 3, a simplified geological NW-SE cross section is presented, showing the geological layer discreatization in the developed simulation model. The waste material was not present in the entire modeled area therefore it was chosen to be described not as a layer but as a lens of material with different hydraulic and soil characteristics at a specific area within layer 3 . The depth of the various geological formations was imported into the model considering that PTC algorithm accepts only positive elevation values. For that reason, a zero elevation level was set $(0.00 \mathrm{~m})$ and absolute elevation values for all layers were properly modified. The different geological formations present in the modeled area are characterized as (ATTIKO METRO S.A., 1997):

- Geological basement: Impermeable Athenian schist,

- Layer 1: Low permeability neogene deposits including marls and siltstones,

- Layer 2: High permeability in the upper part of the neogene deposits and in the lower part quaternary deposits (consisted of sand gravel, clayey sand and gravel),

- Layer 3: Low permeability quaternary deposits (consisted of sandy gravel and silt),

- Layer 4: High permeability manmade deposits.

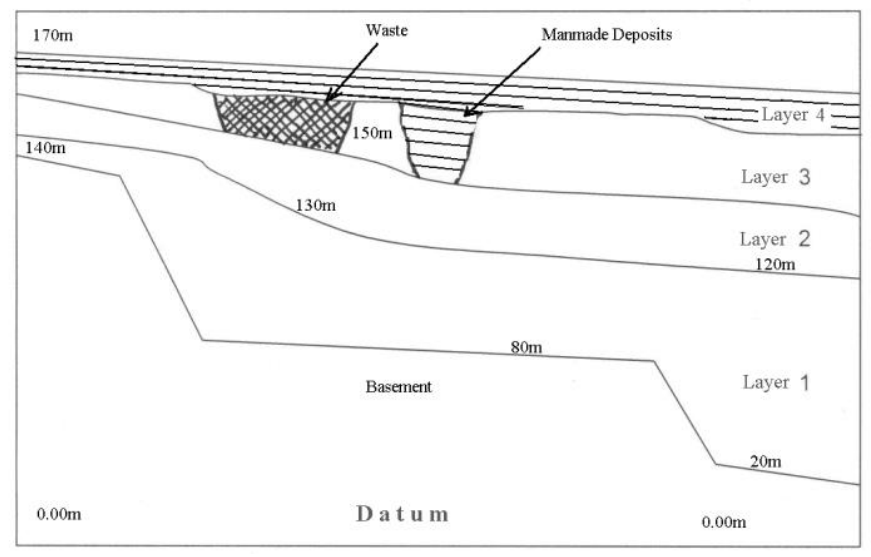

Figure 2. Simplified geological cross section (no scale)

In order to determine flow and mass transport boundary conditions, water level, contaminant concentration field measurements and pumping data were collected. No-flow boundary conditions (bc) were set in the southern, eastern and western boundaries of model domain whereas in the northern and southeastern part of the domain, a $1^{\text {st }}$ type flow bc was set based on water level values observed in existing piezometers in the modeled area prior to any construction works. The existing pumping activity inside the modeled area was set as $2^{\text {nd }}$ type flow bc. Also, the contaminant plume evolution was approximated considering buried solid wastes as a constant source of ammonium.

Table 1. Hydraulic parameters for each layer of the model

\begin{tabular}{lcccc}
\hline & $\begin{array}{c}\text { Hydraulic Conductivity } \\
\mathrm{K}\left(\mathrm{m} \mathrm{day}^{-1}\right)\end{array}$ & $\begin{array}{c}\text { Storage Coefficient } \\
\mathrm{S}\end{array}$ & Porosity $\mathrm{n}$ & Dispersivity \\
\hline layer 1 & 0.432 & 0.005 & 0.05 & 0.1 \\
layer 2 & 864 & 0.05 & 0.1 & 1 \\
layer 3 & 0.432 & 0.001 & 0.01 & 0.1 \\
layer 4 & 8.64 & 0.01 & 0.1 & 0.9 \\
\hline
\end{tabular}

The physical system was estimated to reach steady state conditions very fast so initial conditions were assumed constant over the entire domain. Model parameters were obtained from in-situ field measurements and water sample chemical analyses and they were deterministically set (Table 1). 
Additionally the simulated aquifer was considered as confined and precipitation rate was set equal to $400 \mathrm{~mm} \mathrm{yr}^{-1}$.

\subsection{Simulation stages}

a) $1^{\text {st }}$ Stage

The calibration of the developed groundwater simulation model was obtained based on conditions observed prior to any construction activity (ATTIKO METRO S.A., 1997).

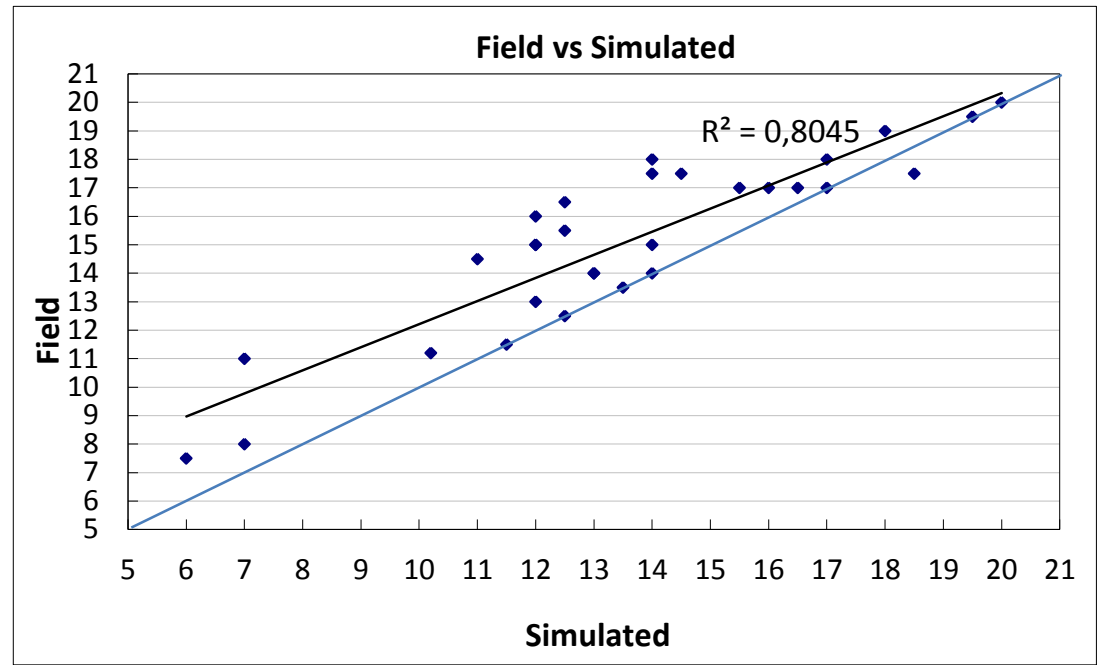

(a)

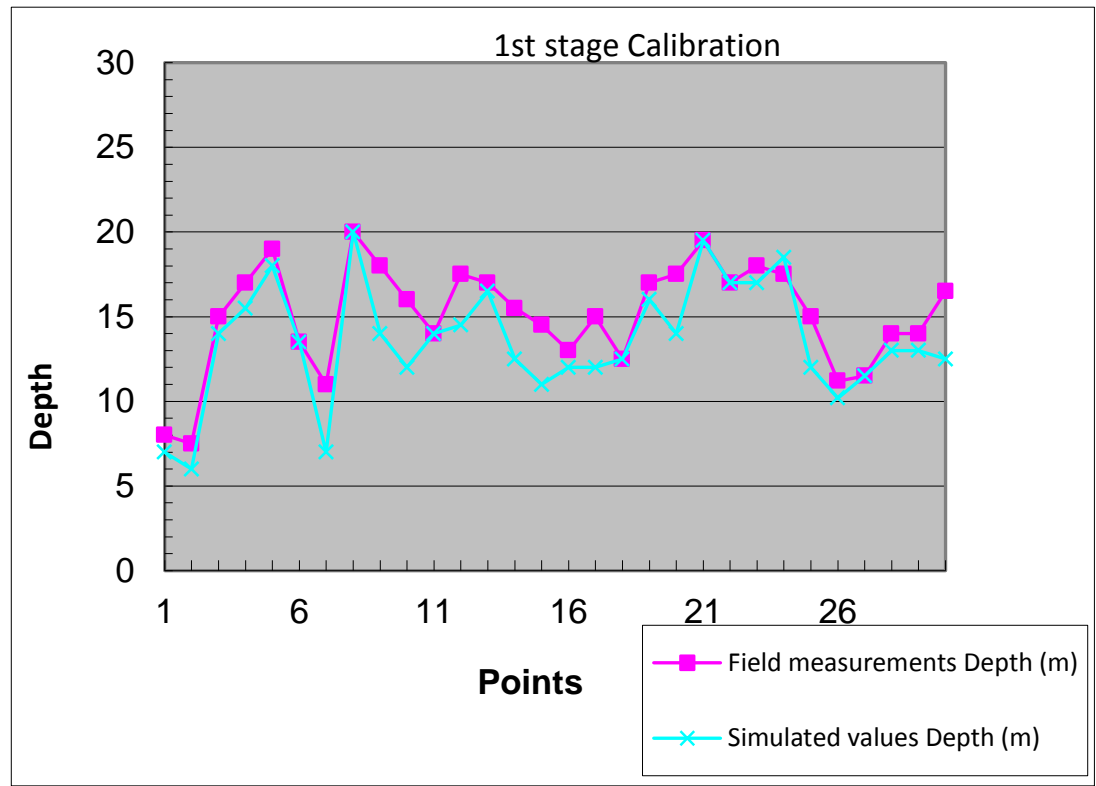

(b)

Figure 3. Field water level measurements vs. simulated water level values

Calibration results (Figure 3a) showed a good correlation between field water level measurements and simulated water level values $\left(R^{2}=0.8\right)$, mainly in the high interest central part of the modeled area (e.g. points $5,6,11,13,18,26,27,28$ and 29) while there were some deviations in the Northern and Southern sides of the model domain (e.g. points 9, 10, 15, 17, 25 and 30) due to the imposed boundary conditions (Figure 4). As Konikow and Bredehoeft (1992) pointed out in their analysis: "The model is considered calibrated when it reproduces historical data within some subjectively acceptable level of coherence based on one's judgment". Simulated and observed data curves follow a similar trend (Figure 
3b). Unfortunately, the lack of piezometric data in the extended region surrounding the modeled area was crucial in order to accurately describe the aquifer behavior at the boundaries. The uncertainty associated with the imposed boundary conditions affects in some degree the differentiation between simulated and observed water level measurements at the boundaries.

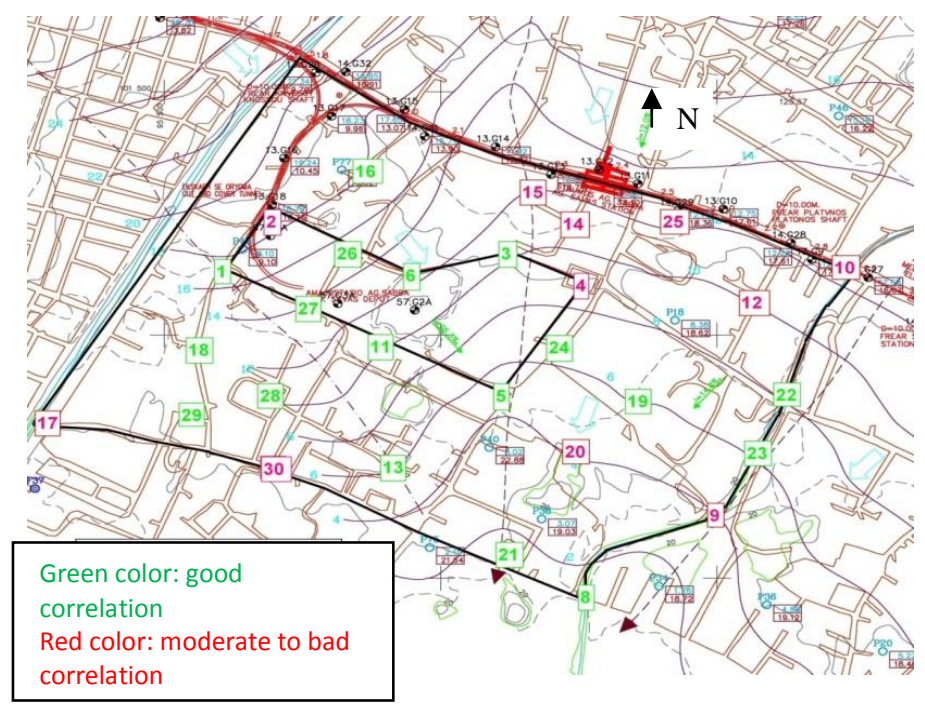

Figure 4. Piezometric map-Calibration results (after ATTIKO METRO, 1997)

b) $2^{\text {nd }}$ Stage

During the $2^{\text {nd }}$ stage, the construction of METRO tunnel from 2003 until 2006 was implemented. The tunnel was represented as impermeable segments placed in layers 2 and 3 along the Northern boundary (zero flow condition - Neumann bc). The rest of the model setup remained as in Stage 1 for a 3-year simulation period.

c) $3^{\text {rd }}$ Stage

In the $3^{\text {rd }}$ Stage, groundwater flow and ammonium mass transport were simulated after the construction of METRO depot and the removal of solid wastes (2006-2009). It should be noticed that buried wastes were only removed from the area where the depot was constructed therefore small but significant quantities of wastes remained buried elsewhere. The depot impermeable walls' were imported into the model (layers 2 and 3 ) as zero permeability soil lenses.

d) $4^{\text {th }}$ Stage - Up to date model prediction

Groundwater flow and ammonium mass transport conditions were simulated for an additional 3-year period in order to update aquifer's behavior up to 2012.

e) Zero Scenario - No construction

Zero scenario was developed to simulate aquifer's behavior in case that METRO facilities were not implemented in the region. In this scenario, the evolution of ammonium plume in the region for a $10-$ year period due to produced waste leachate was estimated. A comparison of ammonium plume evolution with ( $4^{\text {th }}$ stage) and without (Zero Scenario) METRO facilities proved that aquifer soil and groundwater conditions were significantly improved by METRO project implementation due to the removal of large volumes of wastes from the soil and the containment of subsurface water pollution that was achieved.

\section{Results analysis - estimation of contaminant plume evolution}

During the $1^{\text {st }}$ Stage, groundwater flow had a general Northwest to Southeast direction. The main drainage axis ran in the central part of the model from N-NW to S-SE direction and the secondary along Profiti Daniel stream (Figure 5). 


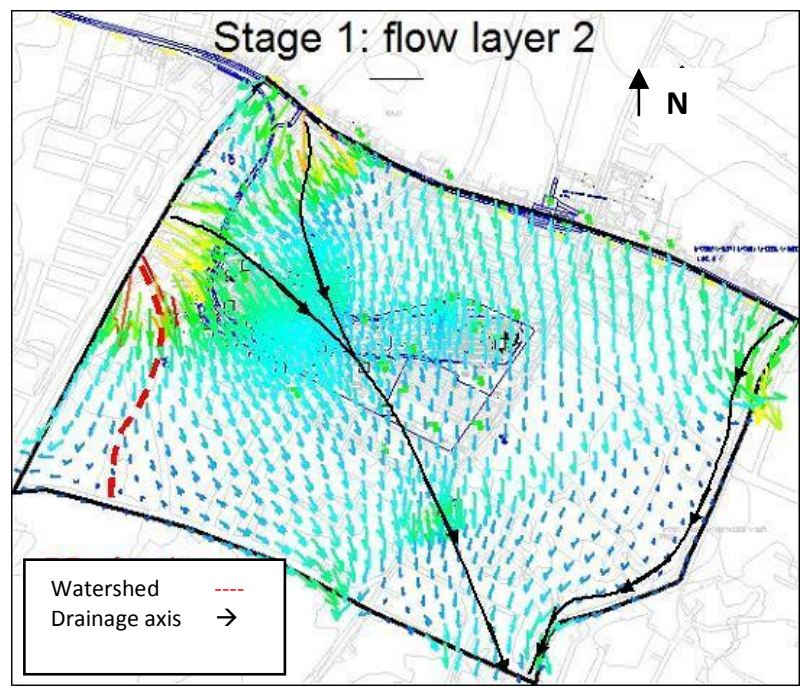

Figure 5. Groundwater flow (Layer 2)
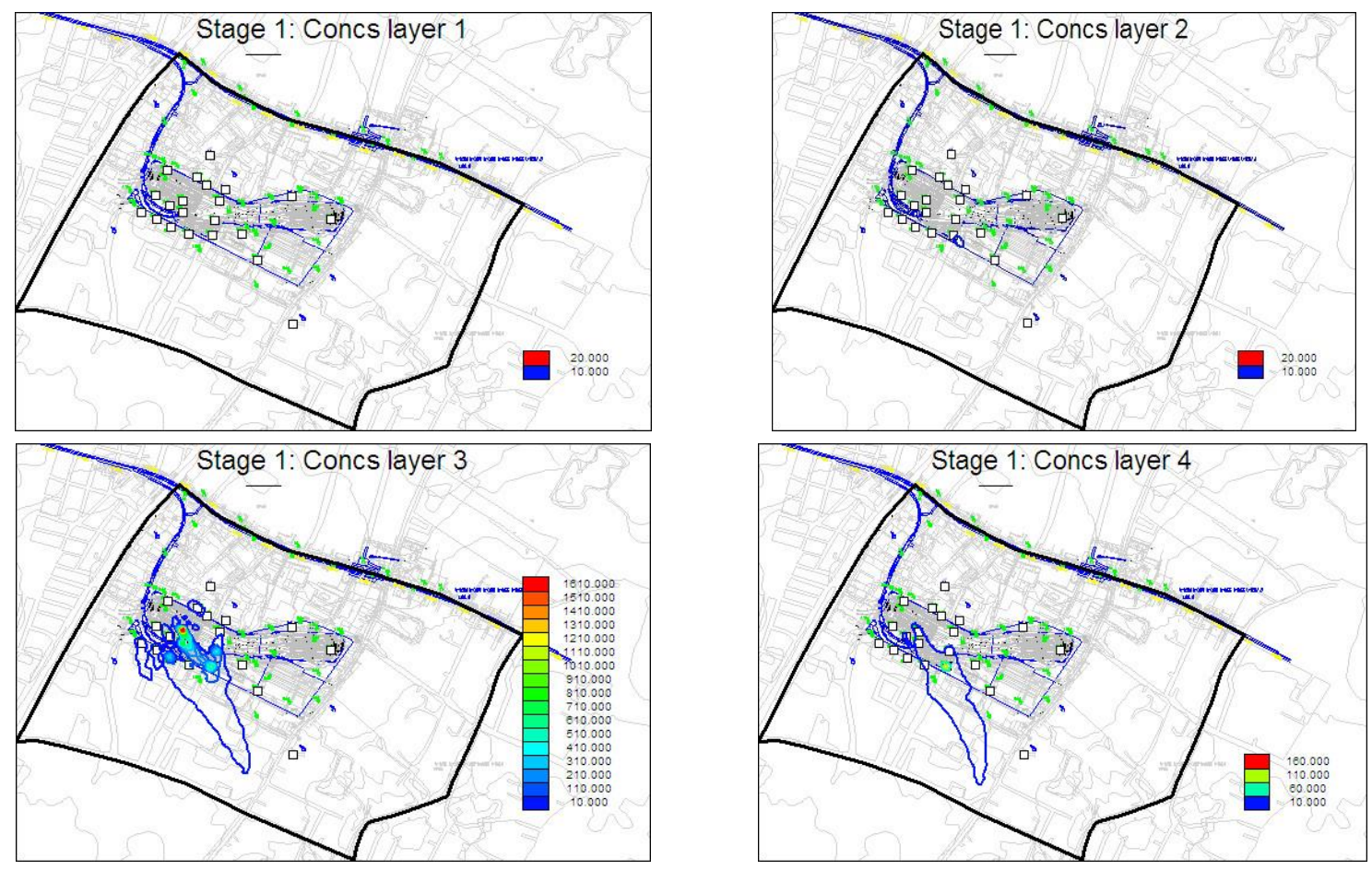

Figure 6. Concentration of ammonium in the 3-D model (Stage 1) - blue line indicates ammonium concentration $>10 \mathrm{mg} \mathrm{I}^{-1}$

The mapping of ammonium plume was based on the maximum allowed value for disposal in natural reservoirs $\left(10 \mathrm{mg}^{-1}\right)$ according to Greek legislation. The simulation results of ammonium contaminant transport in layer 3 (where solid wastes were found) showed that contamination has moved few hundred meters from the main source of pollution following the main groundwater flow direction. The highest value of ammonium concentration in layer 4 was observed south of the main sources of contamination and ammonium plume had the same direction as in layer 3. In the deepest layers 1 and 2 , smaller values of ammonium were simulated $\left(\sim 25 \mathrm{mg} \mathrm{l}^{-1}\right.$ in layer 2 and almost zero in layer 1$)$ indicating limited contaminant leachate from layer 3 downwards due to the existence of low permeability geological formations in these two layers. In layer 2, ammonium concentrations were calculated south of main contamination source, following the main groundwater flow direction (Figure 6). 
During the $2^{\text {nd }}$ stage, METRO tunnel has been constructed along the Northern part of the modeled area and an impermeable boundary (zero flow bc) at layers 1, 2 and 3 was imposed. As result, a significant change in hydraulic field (piezometric lines) in the North part of the construction site has been observed. Especially in layer 2, where the main part of impermeable structure was imposed, significant groundwater flow reduction has been observed due to the existence of underground tunnel that works as a barrier (Figure 7). By slowing down groundwater flow, a limited development of ammonium plume in layer 3 was observed as well as in layer 4 where buried wastes were located (Figure 8).
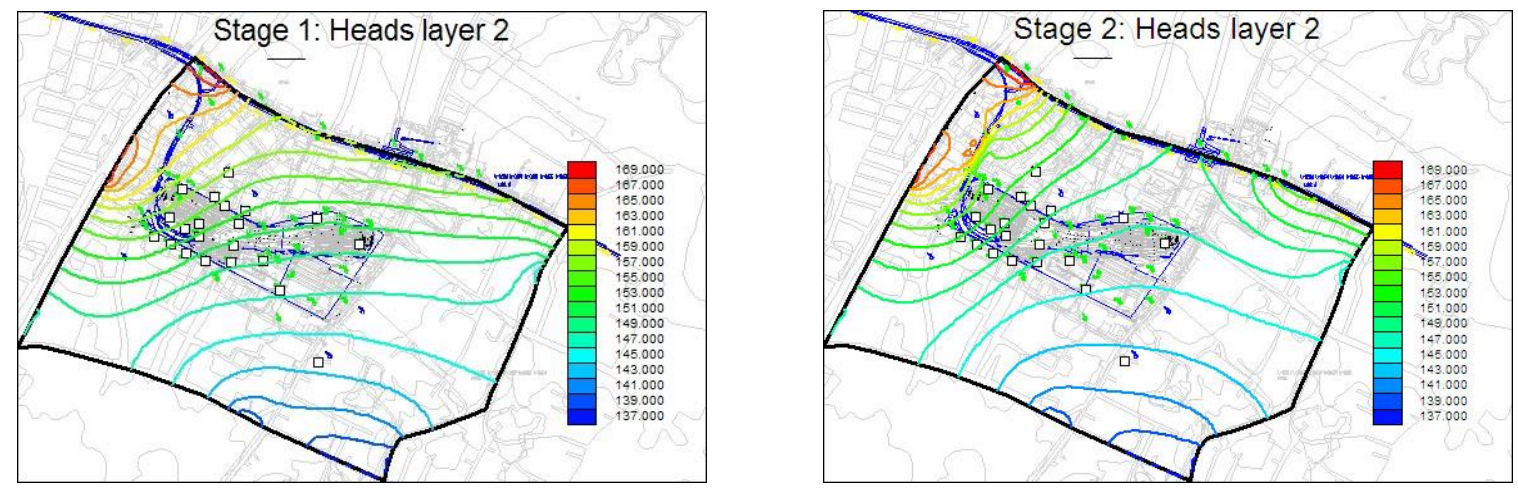

Figure 7. Piezometric field during the $1^{\text {st }}$ and the $2^{\text {nd }}$ simulation stages (Layer 2)

During the 3rd simulation stage, the impermeable walls of METRO depot were inserted into the model. In order for the depot to be constructed, buried wastes should be prior removed so the sources of contamination within construction zone have been removed whereas outside the depot's perimeter solid wastes still remain buried.
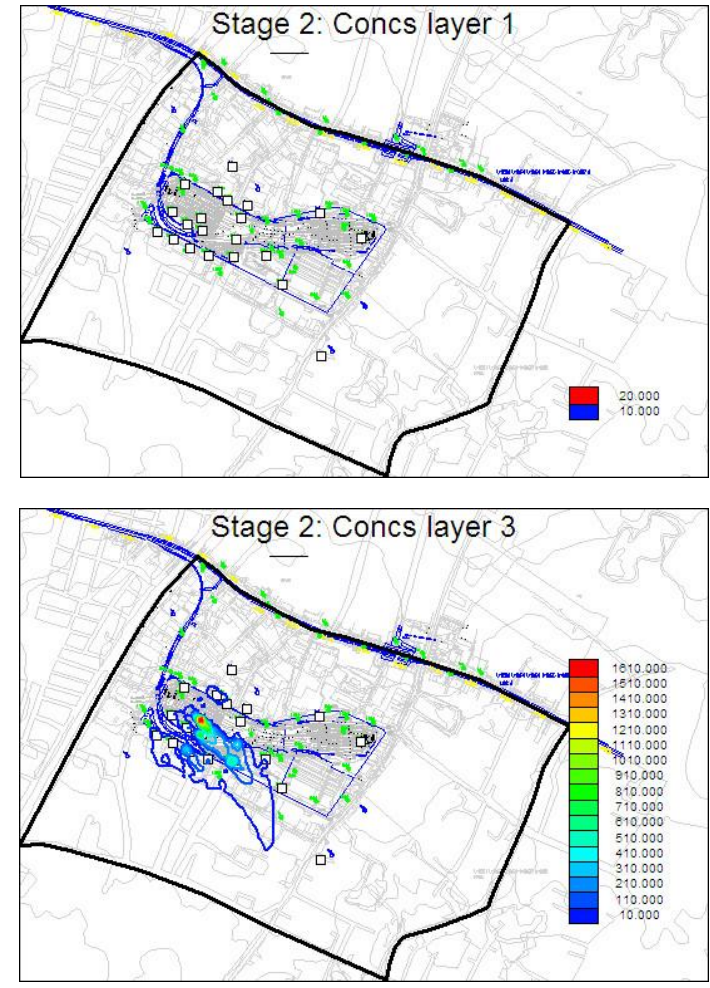
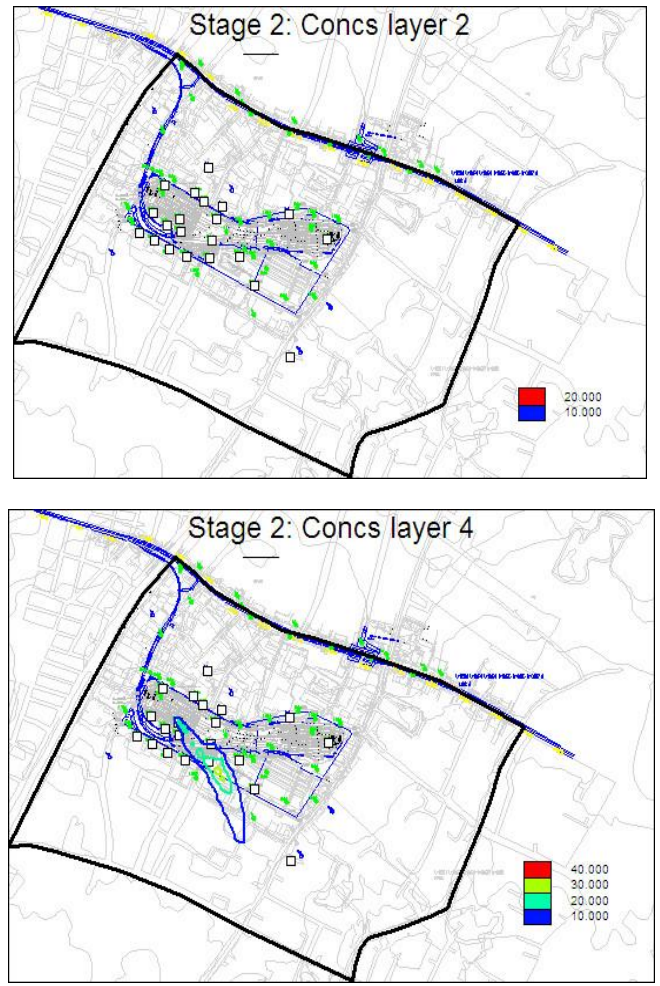

Figure 8. Concentrations of ammonium at the 4-layer model ( $2^{\text {nd }}$ stage)

The ammonium plume development in this stage was slow with a limited spread of contamination. The maximum value of ammonium $\left(300 \mathrm{mg} \mathrm{I}^{-1}\right)$ was calculated in layer 3 at locations south of depot walls 
while dispersion was quite low. The low observed concentration values as well as the small plume extent were due to the construction of depot walls that were working as a barrier to groundwater flow south of the depot. It should be mentioned that small but significant quantities of wastes remained in the area but due to the underground tunnel construction; groundwater flow was significantly reduced resulting to limited ammonium plume spread.

In the final $4^{\text {th }}$ stage of simulation, the behavior of the physical system after the completion of METRO infrastructure project was simulated. During this 3-year period, groundwater flow was constant and ammonium contamination problem was mostly solved even though small quantities of wastes in layer 3 have not been removed causing a limited contamination (Figure 9).
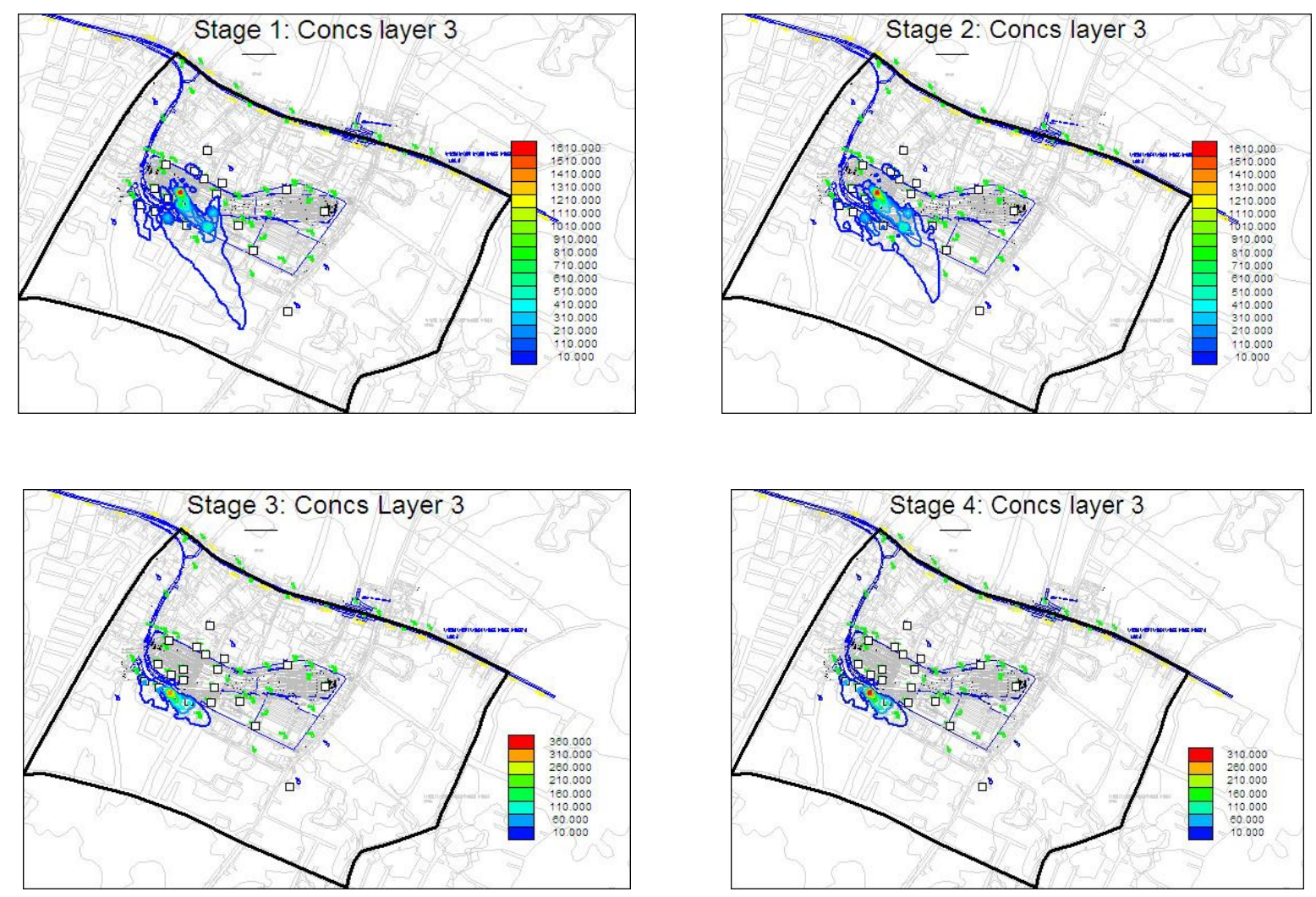

Figure 9. Ammonium plume spread during the 4 stages of simulation model (Layer 3)

\section{Discussion}

Most of the times, the cost of preventive measures is 10 to 20 times lower than the necessary funds to clean up a polluted aquifer (Rasula and Rasula, 2001). Therefore the development of a monitoring system that will regularly record the quality of territorial and water resources in a large scale infrastructure project such as a highway, a sanitary landfill and an industrial zone is mandatory in order to meet the imposed environmental requirements. Rasula and Rasula (2001) proposed a hydrogeological approach for the establishment of an active groundwater quality monitoring system in linear zones of infrastructure facilities. Calo and Parise (2009) highlighted the need for a monitoring groundwater system in karstified areas that are particular vulnerable to groundwater pollution. The risk of pollution is extremely high in areas like the one in Mostar, Bosnia-Herzegovina, where for many priorand post- war years hundreds of tons of solid and toxic wastes have been discharged in abandoned mining areas operating as uncontrolled dumpsites. As far as monitoring groundwater quality in an infrastructure facility, Pandey et al. (2011) went a step forward by proposing a groundwater sustainability infrastructure index (GSII) as a measure of groundwater sustainability. The GSII is 
composed by five components related to groundwater monitoring, knowledge generation and dissemination, regulatory interventions, public participation and institutional responsibility. Even though the components of GSII are quite universal, their study have shown that in order to obtain comparable results between different cases a sensitivity analysis of GSII is mandatory

The construction works that took place from 2002 till 2009 in the greater Eleonas region in Attikis Greece showed that the removal of solid wastes in combination with remedial actions such as soil replacement significantly improved the environmental conditions in this aquifer. In the case of no METRO project implementation (Zero scenario) the plume extent would have been much larger (Figure 10). It should be noticed that after the end of the construction during the $4^{\text {th }}$ stage of simulation, small quantities of wastes south of METRO depot remained buried into the aquifer justifying the existence of low concentration ammonium values there. In conclusion the containment of the ammonium plume was obtained after remedial actions taking to protect the territorial resources of the region during the infrastructure project. Otherwise, if the construction of METRO depot has being postponed ammonium plume would had been extended outside the property boundaries creating serious environmental problems in the greater region.
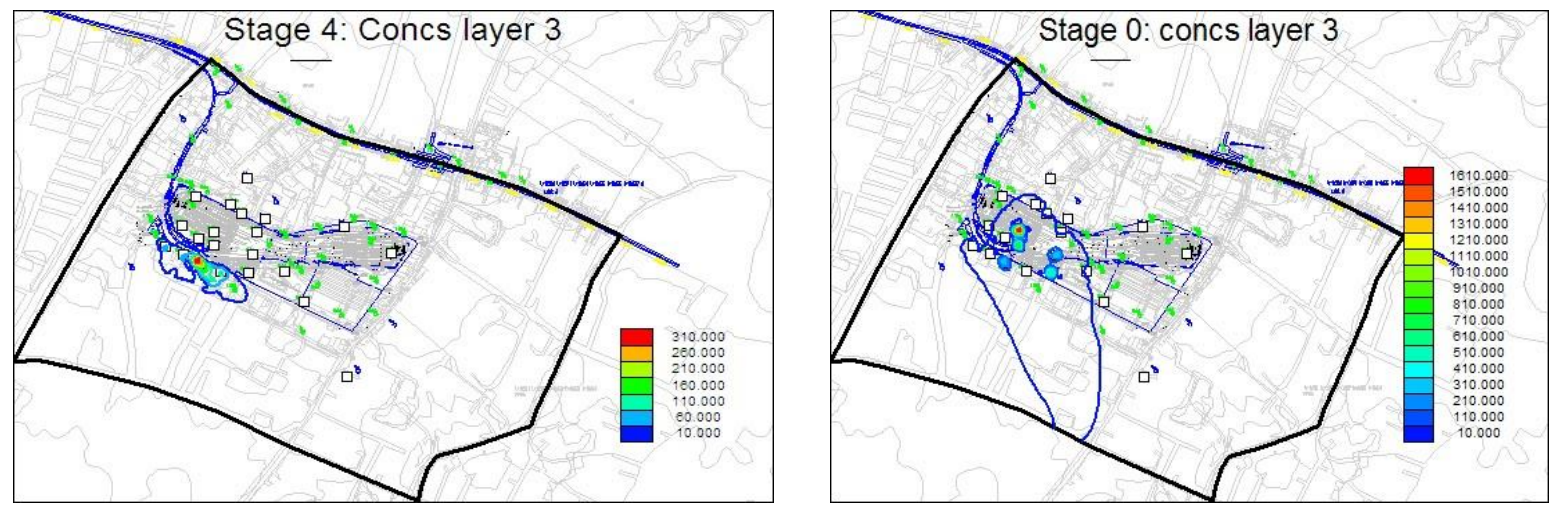

Figure 10. The simulated ammonium plume extent with $\left(4^{\text {th }}\right.$ Stage) and without (Zero scenario) the implementation of the METRO infrastructure facility (Layer 3)

\section{Evaluation of methodological approach - Suggestions}

The simulation results were in a good agreement with the results of the environmental investigation obtained by ATTIKO METRO S.A. even though the boundaries of ATTIKO METRO S.A. property where the environmental investigation took place do not coincide with the boundaries of the modeled area.

By using PTC mathematical algorithm, the area of interest was well enough simulated as far as groundwater flow and ammonium mass transport fields. Nevertheless, in order to create a realistic model, certain assumptions were made. The changes in groundwater flow and contaminant mass transport processes were gradually obtained since the transition of the physical system from one implementation stage to another was not instantaneous; there was always a time period of construction works between the various construction phases that could not be easily represented during the simulation process. Additionally, there was limited quantitative and qualitative groundwater data for the period after wastes' removal.

Some suggestions coming out from this analysis as far the protection of the environment in the greater area of interest are:

a) the design of an environmental monitoring program in order to analyze soil and water quality data in a regular basis and 
b) the implementation of a groundwater quality monitoring system, especially in the region south of METRO depot that could decisively contribute in an accurate model verification and an environmental impact assessment of the construction activities.

Finally, among the priorities of ATTIKO METRO S.A. is the construction of a water runoff network which will dramatically contribute to the improvement of water quality in the surrounding area (ATTIKO METRO S.A., 2009).

\section{Conclusions}

In conclusion, the findings of this analysis proved that the implementation of a large transport infrastructure project like the construction of METRO facilities (tunnel, station and depot) in Eleona Attikis Greece could act environmentally beneficial for the region. On the occasion of the construction of METRO depot, a large scale contamination problem of soil and water resources in the region was revealed. The existence of buried wastes poses serious risks to the quality of soil and subsurface water resources in the region resulting in significant impact on public health. The project implementation imposed removal of significant amounts of buried solid wastes reducing environmental burden in the aquifer. In the authors knowledge there is no documented case in the literature of such a large transportation infrastructure project which may have significant effects on the improvement of soil and water resources in an urban area.

\section{Acknowledgements:}

The authors would like to thank the ATTIKO METRO S.A. for providing them the necessary data for the implementation of this study

\section{References}

Abu-Rukah Y. and Al-Kofahi O. (2001), The assessment of the effect of landfill leachate on ground-water quality - a case study. El-Akader landfille site- north Jordan, Journal of Arid Environments, 49, 615-630.

Albaiges J., Casado F. and Ventura F. (1986), Organic indicators of groundwater pollution by a sanitary landfill, Water Research, 20, 1153-1159

ATTIKO METRO S.A., 1997. Geological and Hydrogeological Study, - Extension Project Phase 1, Western Extension of line 3 Keramikos - Egaleo, Edafomichaniki EPE (in Greek)

ATTIKO METRO S.A, 2005. Final Report of Presentation of Environmental Investigation, Edafomichaniki EPE (in Greek)

ATTIKO METRO S.A, 2009. Engineering Geology Study and Hydrogeological Study, Edafomichaniki EPE (in Greek)

Babu D.K., Pinder G.F., Niemi A., Ahlfeld D.P. and Stothoff S.A., 1997. Chemical Transport by Three-Dimensional Groundwater Flows, Princeton University, 84-WR-3, USA.

Calo F. and Parise M. (2009), Waste management and problems of groundwater pollution in karst environment in the context of post-conflict scenario: The case of Mostar (Bosnia Herzegovina), Habitat International, 33, 63-72.

Chang S.W. and Clement T.P. (2013), Laboratory and numerical investigation of transport processes occurring above and within a saltwater wedge, Journal of Contaminant Hydrology, 147, 14-24.

El-Fadel M., Findikakis A. and Leckie J. (1997), Modeling leachate generation and thransport an solid waste landfills, Environmental Technology, 18, 669-686.

Fatta D., Naoum D. and Loizidou M. (2002), Integrated environmental monitoring and simulation system for use as a management decision support tool in urban areas, Journal of Environmental Management, 64, 333-334.

Jhamnani B. and Singh S.K. (2009), Groundwater contamination due to Bhalaswa Landfill site in New Dehli, International Journal of Civil and Environmental Engineering, 1:3, 121-125.

Konikow L.F. and Bredehoeft J.D. (1992), Ground-water models cannot be validated, Advances in Water Resources, $15,75-83$. 
Lolos T., Koullapis G., Lolos G., Paschali - Manou K., Tsobanidis C., Georgiou I. and Panagopoulos A., 2007. Risk Assessment and Evaluation of uncontrolled landfill sites in Cyprus, E-proceedings of $1^{\text {st }}$ Conference on Environmental Management, Engineering, Planning and Economics (CEMEPE) Skiathos Island, Greece.

MacFarlane D.S., Cherry J.A., Gillham R.W. and Sudicky E.A. (1983), Migration of contaminants in groundwater at a landfill: a case study, 1. Groundwater flow and plume delineation, Journal of Hydrology, 63, 1-29.

Marinos P., 2004, Expert Technical Report TSA263 EEE\#004: Ag. Savvas Depot. Evaluation of hydrogeological conditions (in Greek)

Mato, R.R.A.M., 1999. Environmental implications involving the establishment of sanitary landfills in five municipalities in Tanzania: The case of Tanga municipality, Resources Conservation and Recycling, 25, 1-16.

Nelson N.T., Hu Q. and Brusseau M.L. (2003), Characterizing the contribution of diffusive mass transfer to solute transport in sedimentary aquifer systems at laboratory and field scales, Journal of Hydrology, 276, 275-286.

Odukoya A.M. and Abimbola A.F. (2010), Contamination assessment of surface and groundsurface within and around two dumpsites, International Journal of Environmental Science and Technology, 7(2), 367-376.

Pandey V.P., Shrestha S., Chapagain S.K. and Kazama F. (2011), A framework for measuring groundwater sustainability, Environmental Science and Policy, 14, 396-407.

Papadopoulou M.P., Karatzas G.P. and Bougioukou G.G. (2007), Numerical modeling of the envir onmental impact of landfill leachate leakage on groundwater quality - A field application, Environmental Modeling \& Assessment, 12(1), 43-54.

Pastor J. and Hernández A.J. (2012), Heavy metals, salts and organic residues in old solid urban waste landfills and surface waters in their discharge areas: Determinants for restoring their impact, Journal of Environmental Management, 95, S42-S49.

Pinder G., 2002, Modelling of Groundwater Systems using Geographical Information Systems, John Wiley and Sons Inc, New York, 233p.

Rasula G. and Rasula M. (2001), Groundwater quality monitoring system in zones of infrastructure facilities, Engineering Geology, 60, 351-360.

Reinhard M., Goodman N.L. and Barker J.F. (1984), Occurrence and distribution of organic chemicals in landfill leachate plumes, Environmental Science and Technology, 18, 953-961.

Rouholahnejad E. and Sandrnejad S.A. (2009), Numerical simulation of lechate transport into the groundwater at landfill sites, Proceedings of $18^{\text {th }}$ World IMACS/MODSIM Congress, Cairns, Australia pp. 4135-41.

Sharma P.K. and Dixit U. (2013), Contaminant transport through fractured-porous media: An experimental study, Journal of Hydro-environment Research, http://dx.doi.org/10.1016/j.jher.2013.08.003.

Tchobanoglous G. and P. O’ Leary, 2002. Landfilling, Handbook of Solid Waste Management, 2nd Edition, Mc GrawHill

Venkatachalam L. (2004), Sources of government failure and the environmental externality: analysis of groundwater pollution in Tamil Nadu, India, Water Policy, 6, 413-426.

Verwiel M., Thrupp G., Purdy S. and Rogers S. (2001), Landfill expansion beneath the water table in central Arizona, Proceedings of 8th International Waste Management and Landfill Symposium, CISA, Cagliari Italy.

Vourdias E.A (2001), Pump-and-Treat remediation of groundwater contaminated by hazardous waste: Can it really be achieved?, Global Nest: The International Journal, 3(1), 1-10.

Wei X., 2006. Long-term Monitoring Network Design Evaluation Using and Intermediate-Scale Groundwater Facility, Ph.D. Dissertation, Dept. of Civil and Environmental Engineering, University of Vermont

WHO, 2003. Ammonia in drinking-water. Background document for preparation of WHO Guidelines for drinkingwater quality. Geneva, World Health Organization (WHO/SDE/WSH/03.04/1). 